\title{
Theorising the Private Sphere
}

\section{Book Review}

\section{Peter Goodall}

MACQUARIE UNIVERSITY

Beate Rössler (ed.)

Privacies: Philosophical Evaluations

Stanford, California: Stanford University Press, 2004

ISBN 0-8047-4564-I

RRP US\$22.95 (pb)

This volume of essays is based on papers delivered at a conference on the theme of 'New Perspectives in Privacy' held at the Amsterdam School for Cultural Analysis in 1999. In her introduction, Beate Rössler outlines six different approaches to the topic of 'privacy': theories of the public sphere such as Jürgen Habermas's; theories of civilisation such as Norbert Elias's; sociological studies of private life, especially the family; feminist critiques of traditional liberal distinctions between the cultures of the public and private worlds; information theory; and the vast and varied law of privacy. This book consciously eschews the first category, and it is clearly at its strongest when dealing with privacy law and with the philosophy of privacy. Ten of the thirteen contributors are women, and many of the issues are handled from a feminist perspective. 
Although privacy-related matters, broadly conceived, remain one of the most common areas of legal dispute, it is probably fair to say that the 'law' of privacy is largely an American development of the twentieth century. There is no right to privacy as such in English or Australian law, for example. When Princess Diana wanted to take legal action against the manager of the gymnasium where she worked out and the newspaper that published pictures of her there, there was no law of privacy in England that could protect her, and she had to sue for breach of confidence instead. As Anita Allen traces in her chapter on 'Privacy in American Law', the situation in the USA developed very differently. In 1890, Louis Brandeis and Samuel Warren argued in an influential article in the Harvard Law Review that there was a right to privacy implied in common law. Although many of their arguments from case law were in fact drawn from English legal history, the authors were driven by a sense of apprehension at the potential for intrusion in private life created by the new media of scandal sheets and easily reproducible photographs. It is hard to exaggerate the effect of this article on American legal history, or for that matter the role of Brandeis, who later become a Justice of the Supreme Court, on the law of privacy. In 1905, the state of Georgia became the first in the Union to recognise a right to privacy in its tort law, and this direction has been followed by most US states. Similarly, although the US Constitution does not mention the word 'privacy' as such, privacy interests are widely addressed in the first ten amendments, the Bill of Rights. In the twentieth century, the Fourth Amendment, which guarantees freedom from arbitrary search and seizure of persons and property, and the Fourteenth Amendment, which requires due process of law for any deprivation of a person's life, liberty or property, have been widely used as defences against what many of us would regard as intrusions into our private lives. In the 1960s the Supreme Court gave privacy a central role in the interpretation of the Fourth Amendment. In Griswold vs Connecticut (1965), the court found a fundamental right to privacy in the constitution that is sufficient to prohibit laws criminalising birth control. Most celebrated of all, in the case of Roe vs Wade (1977), the Court found in the Fourteenth Amendment the source of a fundamental right to privacy strong enough to block the categorical criminalisation of abortion.

It is easy to see this as a triumph of liberal humanism, but not everyone has been unequivocally happy about this trend. Some legal theorists and philosophers, not just rightwing ones, have criticised the tendency to see so many kinds of legal interests as privacy interests, and have argued for a restriction of privacy law to those situations in which physical or informational intrusion is the issue. From a communitarian perspective, the privacy interests of individuals are frequently in tension with the public good. Privacy advocates attacked the HIV testing of newborn babies and they opposed mandatory 
government access to encryption keys in electronic means of communication. In the case of DeShaney vs Winnebago Department of Social Services (1989), the Supreme Court agreed that the state government need not take responsibility for the serious consequences of failing to remove a boy from his family home in which he had been severely beaten by his father. Most of all, feminists have criticised the underlying assumption of US privacy law that the family home, the private sphere par excellence, is a necessary haven from a cruel and hostile outside world, a place that guarantees safety no matter what the depredations and cruelty of the public sphere. In ancient times Aristotle saw the private life of the home as a place of tyranny outside the legal framework of the public sphere, and generations of American feminists from the time of Charlotte Perkins Gilman onwards have come to a similar conclusion, satirising the darker sides of private life in which the home is a prison and place of torture rather than a place of safety. Rössler's critique of the liberal tradition of thought about privacy in her chapter on 'Gender and Privacy' draws attention to what she calls the gender paradox of liberal theory, in which privacy is 'the justification of the equality of every human being ... [but] a right [granted] only to adult men'. (55) Other contributors to the volume make similar points. One interesting variant is Jean L Cohen's study of the remarkable change in understanding the notion of the 'domain of intimacy' in the last forty years. As women have entered the workforce in large numbers and marriage has been decentred in the sphere of sexual relationships, many aspects of the traditional domain of private life have entered the public sphere. Sexual harassment legislation has sometimes played an ambivalent role in this context. There has again been a liberal dilemma: on the one hand, intimate relations are a matter of personal choice, protected by basic privacy rights; on the other hand, intimacy can be a site of power relations as well. Not all feminists have seen sexual harassment legislation as the best way forward, however--Judith Butler is an obvious example. Cohen takes issue with the way in which many employers have developed repressive and intrusive 'rules' of sexual behaviour in the workplace in order to guard themselves against litigation. For Cohen, many of these sex codes are founded in a puritanical attitude that sex is bad per se and that women are victims in need of protection, not just against the aggression of male sexuality but also against their own sick desires.

If the discussion of the law and philosophy of privacy is the strong point of the collection--the book is subtitled 'philosophical evaluations'--it is not too hard to see what are some of its weaknesses. Although the book is part of a series called 'Cultural Memory in the Present', there is very little historical perspective on the issue of privacy: few of the essays have any historical range or reference, except for Allen's essay on US privacy law, which includes data from the nineteenth century. There is a sense throughout the book that 
privacy is part of the problematic of 'modernity', but modern is unproblematically associated with an unhistoricised present. In fact, it is much better when discussing privacy to use modern in the way that historians commonly do, referring to the period from about 1500 in western Europe, roughly corresponding to the Renaissance and its aftermath. Curiously, the illustration on the cover of the paperback illustrates this very well: a seventeenth-century Dutch interior, in which one of the maids of a bourgeois house is pointing mischievously to an alcove where a man and a woman are embracing. It was in this period that the private 'home' as most of us understand it, with its private rooms and sense of domestic space, its opportunities for the exercise of physical intimacy and solitude, was first created. It is unfortunate that none of the articles really takes up the history of the formation of privacy as a physical reality rather than as a mental state. Likewise, there are no contributions on the psychology of personal space despite the long history of the study of this topic since Edward Hall's work in the 1960s. There is no anthropology to give a sense of the various ways in which non-western cultures construct private spaces or autonomous selves. Nor is there any discussion of the 'representation' of privacy in literature or art or of its long linguistic history in English since the Middle Ages.

Some of these criticisms are taken up in an essay on 'old age, extended care, and privacy' by Iris Marion Young. She criticises there what she calls the discussion of privacy as a 'virtual' phenomenon, as if it were simply a cognitive or mental state. Young's article--inevitably entitled 'A Room of One's Own'--is an attempt to draw the collection in the direction of some of the material bases of privacy through the study of the personal space made available to the elderly in nursing homes. As she points out, 'for many people ... their primary privacy problem is that they do not have a home'. (181) Her personal recollection of her stepfather's loss of independence is a depressing narrative, but it also offers an invigorating contrast in style to the abstract nature of many of the articles. The loss of personal space even in a 'good' nursing home can essentially destroy the elderly and infirm. Young's stepfather had ten different roommates in the years he lived in a nursing home, his bathroom was shared with five other residents, his room had a door that was never closed, and staff and other residents wandered in constantly. Young's conclusion is that to the extent that the elderly are deprived of personal space in which genuinely to conduct private lives, 'they have a truncated capacity for the formation and maintenance of a sense of person hood'. (181)

The theme of Young's essay may seem old-fashioned--speaking of personhood rather than subjectivity and understanding this as a process in which the individual has considerable agency--but it is a curiously persistent and unavoidable subtext in the collection as a whole. Wendy Brown makes a comment of this nature in her response to Moira 
Gatens's article on 'Privacy and the Body', detecting a tension in Gatens's essay between 'a formulation of the subject radically constructed by historical formations and norms on the one hand, and a more liberal, essential, and self-made subject on the other'. (138) In some ways it is remarkable how resistant the discussion of privacy, especially when it gets down to the details and desires of life as it is lived, is to the poststructuralist project. Gatens's essay counters the abstractness of many of the views of privacy in the collection with a stress on the way in which 'the privacy of individuals cannot be understood independently of the historical specificity of the social and political contexts within which such identities are formed'. (130) Her essay is not really an historical study of privacy, however, although it does exemplify the struggle for personhood and private life as it is presented in two literary classics of autobiography from different places and periods: John Stuart Mill's Autobiography and Sally Morgan's My Place. In her studies of both texts, Gatens stresses how the self remains 'a semipermeable embodied "site," immanently connected to the vast web of more or less collective and anonymous practices, discourses, and affects that constitute various ways of life'. (116) In some ways, the 'web' around Mill's life was vast and complex. He was one of the most 'constructed' men who ever lived, the subject of a planned upbringing, rigorously supervised by his father--Carlyle remarked wickedly that Mill's book read like the autobiography of a steam engine. What Mill's education lacked, of course, was domestic intimacy and emotional life, and eventually he suffered a nervous collapse. Only gradually did Mill learn the 'culture of the feelings' through reading Wordsworth's poetry, and begin to develop an inner life and from there to form friendships with other men and women, to be part of what Gatens terms the 'transindividuality of affect'.

Although this book of essays by different contributors suffers from some limitations of the genre--inconsistency and patchiness of focus, uneven length and quality of individual contributions--it is a useful introduction to some of the theoretical problems and issues that surround the theme of privacy. The interdisciplinary history of privacy in English-speaking culture--a book or series of books fit to stand comparison with Georges Duby's Histoire de la Vie Privée for French--remains, however, as yet unwritten.

Peter Goodall is currently the Acting Dean of Humanities at Macquarie University in Sydney. His publications are mainly on medieval literature and twentieth-century British fiction, especially the work of George Orwell. He has published several articles on the representation of private life in English literature. 